\title{
Obituary
}

a sensational discovery on dynamic equilibration when his fatal illness put an end to his career.

Death is hard for a worker when it strikes him down in the mid-course of his existence. In vain has he freely sown, in vain has he laboriously cultivated the field of his activity, if he reaps no harvest; for he never tastes the joys of a fruitful autumn nor the rest and calm of the winter which ends a happy life.

Marcel LeRMoyez.

\section{RAYMOND VÉREL, O.B.E., M.B., F.R.C.S.E. (AberdeEN).}

By the death of Raymond Vérel, on 29 th September 1920, the specialty in this country has lost one of its young, active, and most promising members. After graduating with honours at Edinburgh University in 1908, Vérel held several general hospital appointments, and also acted as clinical assistant to Dr Logan Turner for eighteen months. He decided to devote himself to the study of Diseases of the Ear and Throat. He proceeded to Vienna for further training, and finally settled in Aberdeen shortly before the outbreak of war. In the autumn of 1914 he effected a transference from the Ist Scottish General Hospital to the Scottish Horse Mounted Brigade Field Ambulance, and served with his comrades at Suvla on the Gallipoli Peninsula. Though invalided home after a severe attack of dysentery, he again saw service in the Desert of Sinai and later in Egypt, where he was made consultant in his special branch. $\mathrm{He}$ served with distinction, and his work and skill were thoroughly appreciated by the numerous patients who passed through his hands. It was not until the summer of 1919 that Vérel was released from his military duties and was able to resume his practice in Aberdeen, where he was almost immediately appointed Aural Surgeon to the Dispensary and to the Royal Hospital for Sick Children, and Lecturer on Diseases of the Ear and Throat.

Unassuming and modest in his bearing, gentle in his handling of children, who seemed specially attracted to him, and possessing a sound knowledge of his subject, he readily gained the respect and confidence of his colleagues and patients. His skill as a manipulator was increased by the fact that he was ambidextrous, a valuable asset to the student of laryngology. To a man of Vérel's personality and professional ability, a successful career was assured. But it has been otherwise decreed, and the promise of these earlier years cannot now bear fruit.

"They shall not grow old, as we who are left grow old; Age shall not weary them, nor the years condemn."

A. Logan Turner. 